\title{
EFFECTS OF TEMPERATURE AND LOAD DURING HOT IMPRESSION BEHAVIOR OF Cr-Ni STAINLESS STEEL
}

\author{
P. Bharath Sreevatsava, E. Vara Prasad, A. Sai Deepak Kumar, Mohammad Fayaz, \\ Anwar, Vadapally Rama Rao, C. Vanitha*
}

Department of Metallurgical and Materials Engineering, NIT Warangal, TS, India.

Received 26.10.2021

Accepted 09.12.2021

\begin{abstract}
Austenitic Stainless steels are majorly used because of their high resistance to aqueous corrosion and high temperature properties. Some major applications of stainless steels at high temperatures include engine and exhaust components in aircrafts, recuperators in steel mills, and pulverized coal injection lances for blast furnaces. In all the above said applications, the components are constantly subjected to loads and high temperatures. This makes the study of their creep behavior very important to decide the life of the component. $\mathrm{Cr}-\mathrm{Ni}$ stainless steel was used as a starting material, and hot impression creep test was performed on cylindrical samples of $10 \mathrm{~mm}$ height and $15 \mathrm{~mm}$ diameter for a dwell time of $150 \mathrm{~min}$ at two different loads of 84 and $98 \mathrm{MPa}$ and at two different temperatures 450 and $500{ }^{\circ} \mathrm{C}$. The time vs. indentation depth was plotted, and creep rate was calculated in each case. It was observed that with an increase in time, creep rate increased in the primary creep region and remained almost constant in the secondary creep region irrespective of temperature and load. The indentation depth and creep rate increased with an increase in load and temperature.
\end{abstract}

Keywords: hot impression creep; load; temperature; creep rate; indentation depth.

\section{Introduction}

Austenitic Stainless steels are mainly used for both high temperature and low temperature service conditions because of it high strength and corrosion resistance. In a conventional creep test, a uniaxial tensile and constant load is applied on a tensile specimen at a constant high temperature above homologous temperature, and strain is measured with an increase in time. But hot impression creep test a constant compressive load applied with the help of a flat cylindrical indenter [1-11].

Donyau Chiang et al. investigated the impression creep behavior of $99.9 \%$ pure single crystal lead using a $100 \mu \mathrm{m}$ diameter punch at ambient and elevated temperatures 
(433-563 K) under punching stresses of 6-70 MPa, and it was also found that recrystallization of lead during the test resulted in a sudden increase of the creep rate and subsequent return to the same final steady impression velocity before recrystallization [12].

Godavarti et al. applied impression creep to a polycrystalline zinc sample and studied the effect of grain size and texture on the three different faces. The activation energy remained the same in all three directions and depended on temperature. It was found to be high at high temperature which was believed to be related to the high temperature creep mechanism, dislocation climb. At low temperatures, activation energy was related to dislocation slip [13]. Naveena et al. emphasized the usefulness of the impression creep technique in the development of creep resistant 316LN ausenitic stainless steel. The impression creep test was performed with different nitrogen contents at $923 \mathrm{~K}$. It was found that steady state impression velocity increased with an increase in punching stress but decreased with the increase in nitrogen content [14]. Gondi et al. performed impression tests on $\mathrm{Al}, \mathrm{Cu}$, AISI 1040 steel, and $\mathrm{Al}-9 \% \mathrm{Si}$, at room temperature, with dispersed $\mathrm{Al}_{2} \mathrm{O}_{3}$ and $\mathrm{SiO}_{2}$ particles with a constant punching velocity [15]. Kiyohiro Ito et al. carried out indentation creep and uniaxial creep tests on ASME Grade 122 steel. The creep exponent and creep coefficient were evaluated as a function of creep damage ratio. A new method was developed to predict the creep life based on creep exponent and coefficient [16].

M.D. Mathew et al. conducted impression creep test on 316LN SS $0.07,0.14$, and 0.22 wt.\% nitrogen at $923 \mathrm{~K}$ under different punching stress conditions and observed that the creep curve obtained from impression creep depth versus time was similar to the creep curve observed in the conventional uniaxial creep test [17]. D. Matschkal-Amberger et al. conducted an indentation creep test on Ni single crystal with 2 at.\% Ta, Re, W at 650 ${ }^{\circ} \mathrm{C}$ by applying stress in the range 85 to $400 \mathrm{MPa}$. The creep properties obtained during indentation creep test agreed with the results obtained conventional uniaxial creep tests [18].

G. Sharma et al. conducted hot hardness and indentation creep tests on Fe-28Al$3 \mathrm{Cr}-0.2 \mathrm{C}$ alloy in the temperature range of $843-963 \mathrm{~K}$. The stress exponent (n) derived from the hardness-time plots was weakly dependent on the temperature. From the values of activation energy and $n$ obtained, the rate controlling creep mechanism was found to be dislocation creep. These values were also in good agreement with previous studies [19].

Modassir Akhtar et al. investigated the short-term impression creep behaviour of Boron modified P91 steel and confirmed that the presence of boron embrittles inter critical heat affected zone after weld simulation, whereas embrittlement shifts to critical heat affected zone after post weld heat treatment. The minimum creep rate value of base metal was higher than of fine grain heat affected zone, but minimum creep rate for fine grain heat affected zone remained equivalent before and after post weld heat treatment [20]. Most of the work on impression creep have been comparative studies with the uniaxial creep, and all their results were in a close match with the results from conventional creep. Therefore, impression creep has become a very reliable creep testing technique in recent years because it has many advantages over conventional tensile creep test, the most important of them being shorter dwell times and less number of samples required to establish the stress temperature relationship and the ability to predict the creep behaviour of a wide range of materials, including brittle materials. There are hardly some 
studies on the hot impression creep behaviour of austenitic stainless steels. Hence it is important to study the hot impression behaviour $\mathrm{Cr}-\mathrm{Ni}$ stainless steels with respect to change in load and temperatures.

\section{Experimental Procedure}

\section{Material}

The chemical composition of the stainless steel used in the present study is given in Table 1.

Table 1. Chemical composition of the stainless steel.

\begin{tabular}{llllllllll}
\hline Elements & $\mathrm{C}$ & $\mathrm{Si}$ & $\mathrm{Mn}$ & $\mathrm{Cr}$ & $\mathrm{Ni}$ & $\mathrm{N}$ & $\mathrm{S}$ & $\mathrm{P}$ & $\mathrm{Fe}$ \\
\hline Wt.\% & 0.08 & 0.8 & 2 & 18 & 8 & 0.05 & 0.03 & 0.05 & balance \\
\hline
\end{tabular}

Hot Impression creep test

The impression creep setup consists of a furnace, lever, indenter Linear Variable Differential Transformer (LVDT) sensor. A cylindrical indenter with a diameter of $2 \mathrm{~mm}$ made up of Inconel was used in the present study. A Cylindrical test sample of $10 \mathrm{~mm}$ height and $15 \mathrm{~mm}$ diameter was hot impression tested for a dwell time of 150 minutes at two different loads of 84 and $98 \mathrm{MPa}$ and at two different temperatures $450{ }^{\circ} \mathrm{C}$ and $500{ }^{\circ} \mathrm{C}$. The actual compression load acting can be calculated from the applied load of 6 $\mathrm{kg}$ and $7 \mathrm{~kg}$ and taking the lever distance into consideration. The stress calculated for the above said applied load has been calculated to be $84 \mathrm{MPa}$ and $98 \mathrm{MPa}$ using the formula:

$$
\text { Impression Stress }=\frac{4 W}{\pi t D^{2}}
$$

Where $\mathrm{W}$ is the applied compression load $(\mathrm{N})$, and $\mathrm{D}$ is the diameter of the indenter [20]. The LVDT sensor measures the indentation depth with respect to time, and indentation depth vs. time graphs were plotted at constant loads and at constant temperatures.

\section{Metallography}

Samples were polished using emery papers of different grades followed by disc polisher. Before hot impression creep test, a sample was etched using Keller's reagent for $40 \mathrm{~s}$, and the initial microstructure was observed under Optical Microscope (OM) and Scanning Electron Microscope (SEM).

$X$-ray diffraction $(X R D)$

Scratch free sample was scanned using an X-ray diffractometer of PANAnalytcal, Model- X'pert machine. $\mathrm{Cu}$ Ka radiation was used for the present study and samples were scanned in the $2 \theta$ range of 40 to $100^{\circ}$. Scanning step size of $0.016711^{\circ}$ was used. Indexing of the obtained XRD pattern was done using X'Pert HighScore Plus software.

\section{Results and discussion}

\section{Microstructural development}

Fig. 1 shows the optical image of the stainless steel in the received condition. It revealed a very fine structure. 


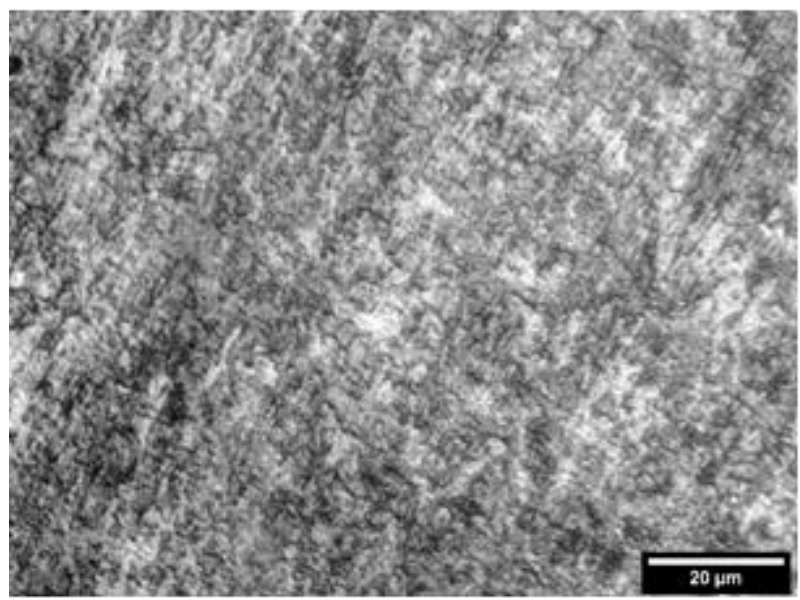

Fig. 1. Optical image of 18-8 stainless steel in the received condition.

\section{Hot impression behavior of Stainless Steel}

The effect of temperature, load, and time on hot impression creep behavior of stainless steel is shown in Fig. 2-4. The indentation depth increased with an increase in temperature from $450{ }^{\circ} \mathrm{C}$ to $500{ }^{\circ} \mathrm{C}$ at a constant load of $84 \mathrm{MPa}$ as shown in Fig. 2(a), 2(b). At constant load, the depth of indentation is more expressive at $500{ }^{\circ} \mathrm{C}$ than at 450 ${ }^{\circ} \mathrm{C}$. It is observed that compared to load, the temperature plays a key role in the depth of indentation. An increase in indentation depth with an increase in time in each case irrespective of the load and temperature was observed. This increase is more significant in the primary creep region as compared to the secondary creep region, where indentation depth remained almost constant with increasing time.

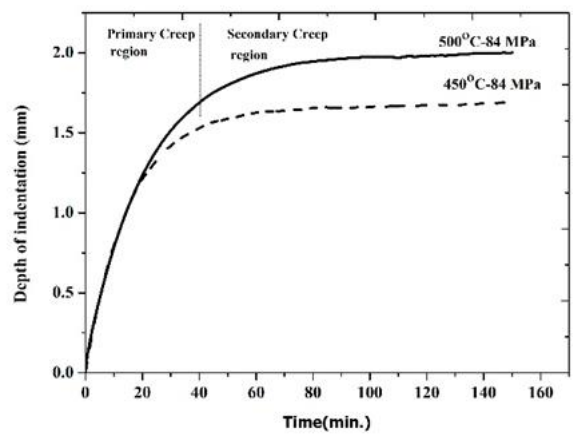

(a)

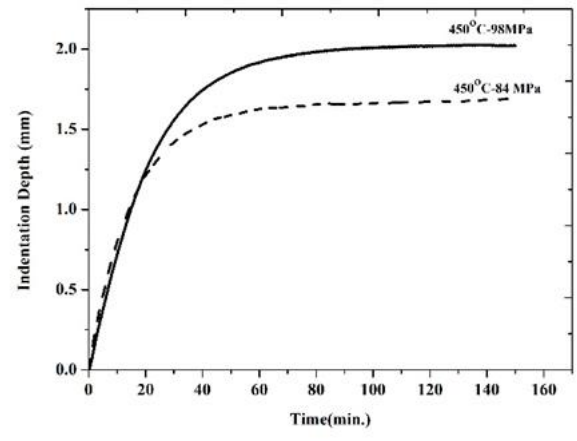

(b)

Fig. 2. The effects of temperature and time on the depth of indentation for various load conditions: (a) $84 \mathrm{MPa}$, and (b) $98 \mathrm{MPa}$.

As shown in Fig. 3(a) and 3(b) with the increase in load from 84 to $98 \mathrm{MPa}$, an increase in indentation depth was observed at constant temperatures of 450 and $500{ }^{\circ} \mathrm{C}$. 


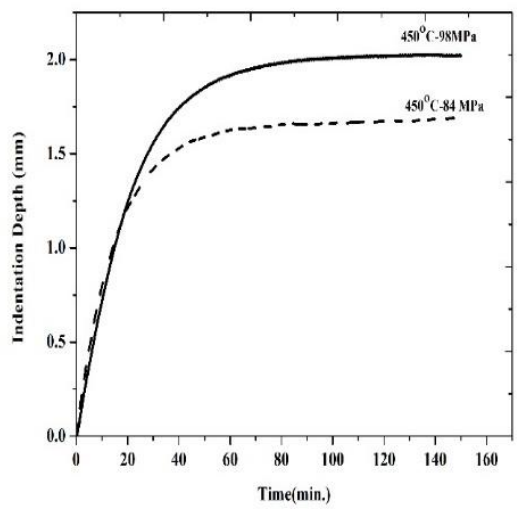

(a)

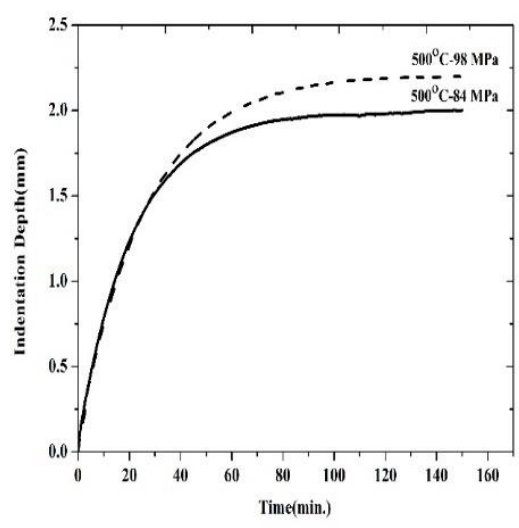

(b)

Fig. 3. The effect of load and time on the depth of indentation at: a) $450{ }^{\circ} \mathrm{C}$, and b) $500{ }^{\circ} \mathrm{C}$.

The creep rate vs. load was plotted at different temperatures is shown in Fig. 4. The creep rate increased with an increase in both temperature and load.

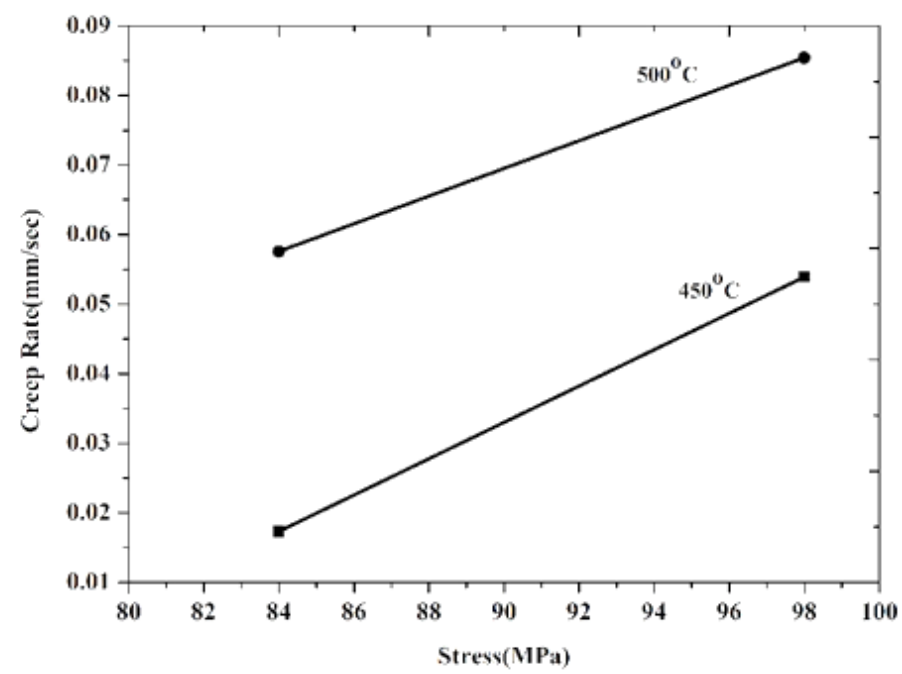

Fig. 4. Effect of temperature and load on steady state creep rate.

Microstructural observation of indentation deformed region

Hot impressed regions of the samples tested at different temperature and load is shown in Fig. 5(a) and 5(b). SEM images reveals that the deformation band at an angle of $45-55^{\circ}$. The band were parallel to each other. Initially, deformation stated with small 
pores, and due to the combined effect of temperature and load the deformation band propaged by interconnecting the pores. The size of the pores was very small at low temperature, and the volume fraction of the volume fraction of the pores and the width of the interconnected deformation band thickness was more for hot impressed sample at high temperature as shown in Fig. 5.

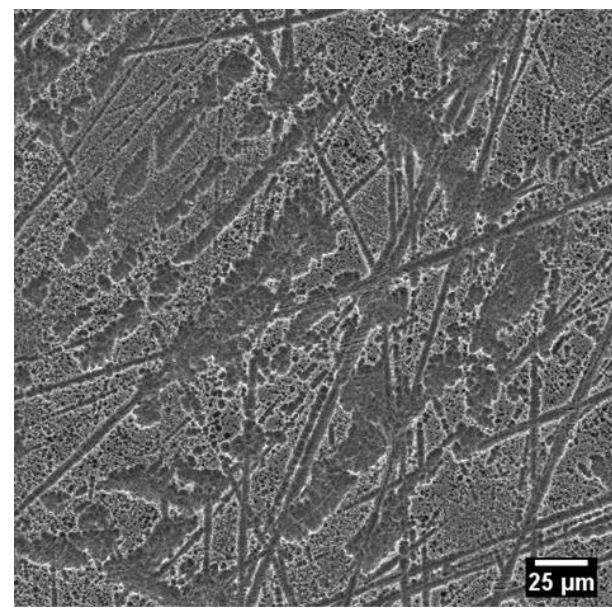

(a)

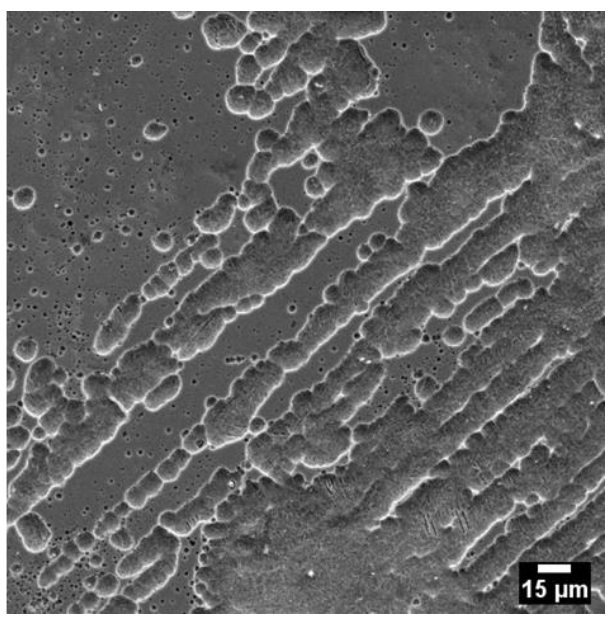

(b)

Fig. 5. SEM image of hot impression tested steel at $84 \mathrm{MPa}$ at: (a) $450{ }^{\circ} \mathrm{C}$, and b) $500{ }^{\circ} \mathrm{C}$.

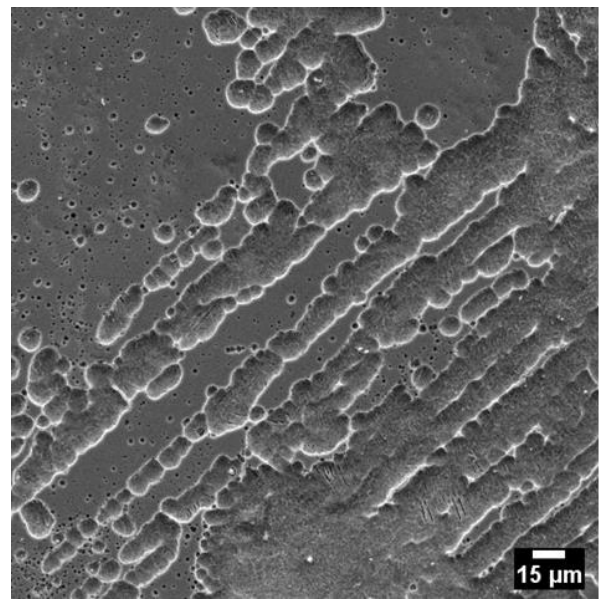

(a)

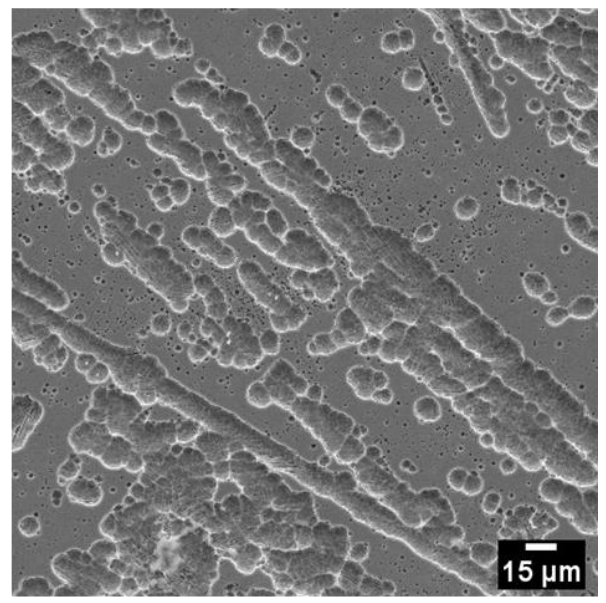

(b)

Fig. 6. SEM image of hot impression tested stainless steel at $500{ }^{\circ} \mathrm{C}$ at different loads (a) $84 \mathrm{MPa}$, and (b) $98 \mathrm{MPa}$. 
As shown in Fig. 6, SEM image of stainless steel hot impressed at $500{ }^{\circ} \mathrm{C}$ with a load of $98 \mathrm{MPa}$ revealed higher volume fraction interconnected deformation band as compared with $84 \mathrm{MPa}$ condition.

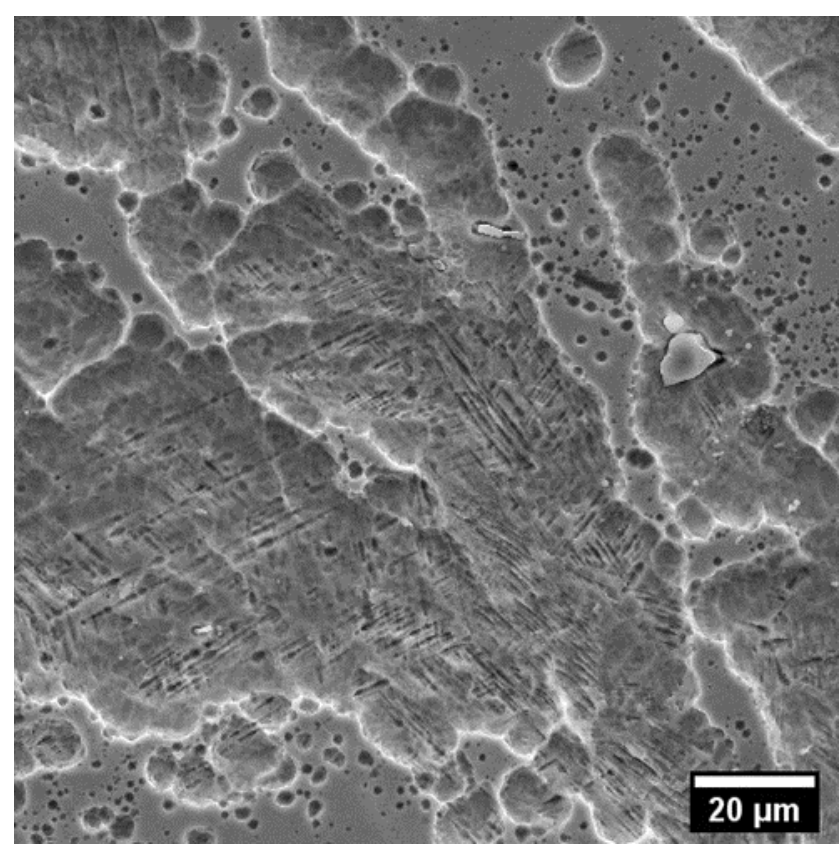

Fig. 7. SEM image of hot impression tested stainless steel at $500{ }^{\circ} \mathrm{C}$ and $98 \mathrm{MPa}$.

Fig. 7 reveals the SEM image of the hot impression tested steel at $500{ }^{\circ} \mathrm{C}$ with 98 $\mathrm{MPa}$ at higher magnification. It was observed that there were needle like substructures inside the interconnected deformed bands and these needle structures were at a certain angle of about $60^{\circ}$ to the deformation band. Fig. 8 shows the EDS spectrum of the sample hot impression tested at $500{ }^{\circ} \mathrm{C}$ with $84 \mathrm{MPa}$. The region with the band structure is marked as $\mathrm{A}$, and non-deformation banded region has been marked as B. Region B revealed the presence of oxygen. It's very clear from the elemental analysis that the presence of oxygen provided the nucleation site of the deformation to begin and propagate. 

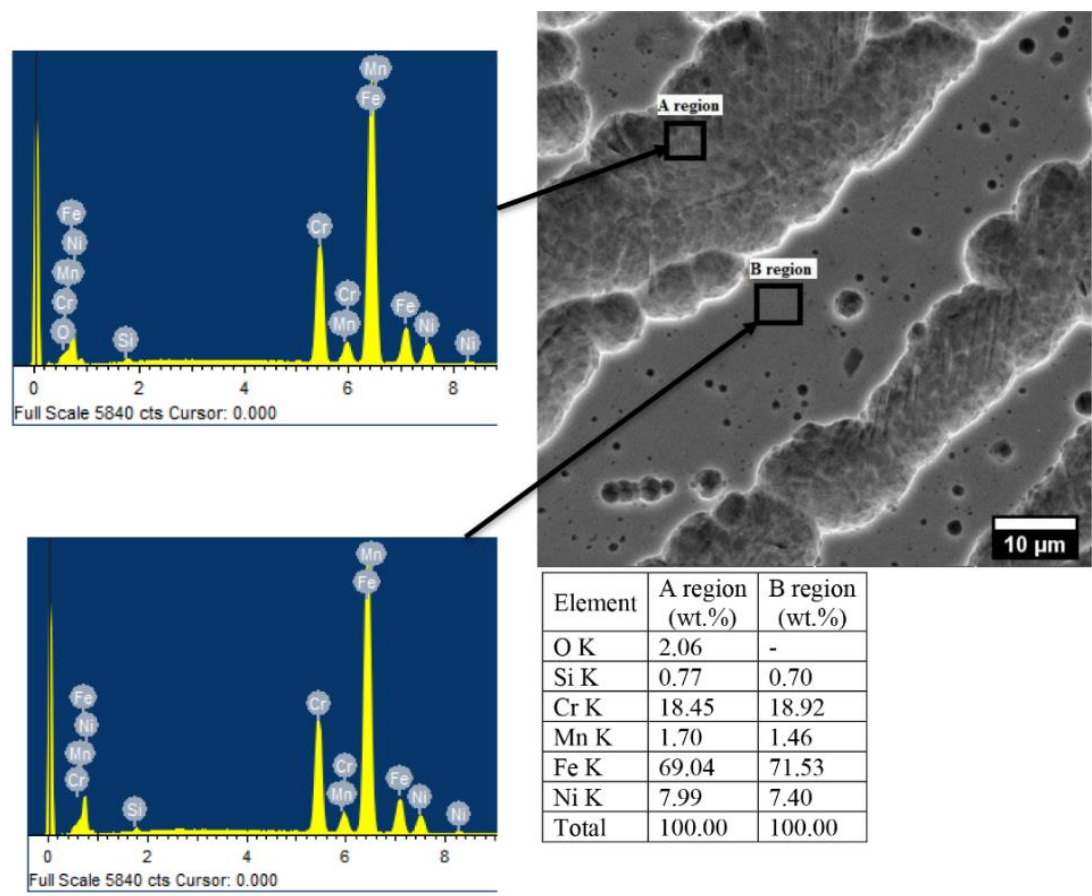

\begin{tabular}{|l|l|l|}
\hline Element & $\begin{array}{c}\text { A region } \\
\text { (wt.\%) }\end{array}$ & $\begin{array}{l}\text { B region } \\
\text { (wt.\%) }\end{array}$ \\
\hline $\mathrm{O} \mathrm{K}$ & 2.06 & - \\
\hline $\mathrm{Si} \mathrm{K}$ & 0.77 & 0.70 \\
\hline $\mathrm{Cr} \mathrm{K}$ & 18.45 & 18.92 \\
\hline $\mathrm{Mn} \mathrm{K}$ & 1.70 & 1.46 \\
\hline Fe K & 69.04 & 71.53 \\
\hline Ni K & 7.99 & 7.40 \\
\hline Total & 100.00 & 100.00 \\
\hline
\end{tabular}

Full Scale 5840 cts Cursor: 0.000

Fig. 8. SEM image and EDS spectrum at indentation area of stainless steel at $500{ }^{\circ} \mathrm{C}$ with $84 \mathrm{MPa}$ for 150 minutes.

XRD pattern of stainless steel impression tested with $98 \mathrm{MPa}$ at 450 and $500{ }^{\circ} \mathrm{C}$ for 150 minutes and then cooled in the furnace is shown in Fig. 9. It revealed the presence of $\gamma$ phase.

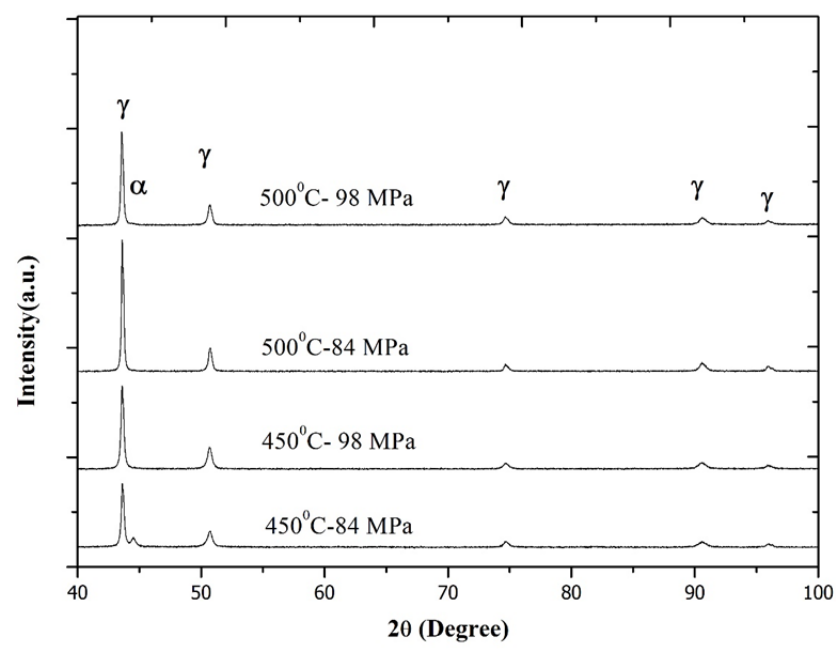

Fig. 9. XRD pattern of stainless steel after hot impression. 


\section{Conclusions}

Indentation depth increased on increasing the impression time, from 84 to $98 \mathrm{MPa}$. The creep rate increased in the primary creep region and remained constant in the secondary creep region in all the cases. SEM images revealed the deformation band at an angle of $45-55^{\circ}$ in the hot impressed region. Deformation bands were parallel to each other. There were fine needles like substructures seen inside the interconnected deformed bands, and these needle structures were at a certain angle of about $60^{\circ}$ to the deformation band. The presence of oxygen provided the nucleation site initiation and propagation of the deformation XRD pattern revealed the presence of $\gamma$ phase in the samples.

\section{References}

[1] S.D. Kumar, M.F. Anwar, E.V. Prasad, P.B. Sreevatsava, C. Vanitha: Mater Today: Proc, 93 (2021) 1292-1302.

[2] S. Kumar, S. Ramteke, S. Chelika, C. Vanitha: Mater Today: Proc, 41 (2021) 1207-1211.

[3] P. Jean, "Sn-Ag-Cu Properties and Creep data", National Institute of Standards and Technology https://www.metallurgy.nist.gov/solder/clech/Sn-Ag$\mathrm{Cu}$ Main.htm; Accessed 1.12.2021.

[4] S.N.G. Chu, J.C.M. Li: J Mater Sci, 12 (1977) 2200-2208.

[5] J.C. Li: Mater Sci Eng A, 322 (2002) 23-42.

[6] D.H. Sastry: Mater Sci Eng A, 409 (2005) 67-75.

[7] M.K. Talari, N. Kishore Babu, K. Kallip, M. Leparoux, R.E. Koller, K.A. Alogab, X. Maeder: Adv Eng Mater, 18 (2016) 1958-1966.

[8] H.Y. Yu, M.A. Imam, B.B. Rath: Micromech. Adv. Mater, (1995), TMS, Warrendale, PA, pp. 237-244.

[9] B. Storåkers, P.L. Larsson: J Mech Phys Solids, 422 (1994) 307-332.

[10] T. R. G. Kutty, C. Ganguly: J Mat Sci, 27 (1992) 908-912.

[11] F.Yang, J.C.M. Li: J Appl Phys, 77 (1995) 110-117.

[12] D. Chiang, J.C.M. Li: J Mater Res, 9 (1994) 903-908.

[13] P.S.Godavarti, K.L.Murty: J Mater Sci Lett, 6 (1987) 456-458.

[14] V.D. Naveena, V. Ganesan, K. Laha, M.D. Mathew: Procedia Eng, 55 (2013) 585590.

[15] P. Gondi, R. Montanari, A. Sili: J Nucl Mater, 212-215 (1994) 1688-1692.

[16] K. Ito, Y. Hiroki, A. Masayuki: Multidisciplinary Digital Publishing Institute Proceedings, 2 (2018) 450.

[17] M.D. Mathew, D. Vijayanand: Journal of materials engineering and performance, 22 (2013) 492-497.

[18] D. Matschkal-Amberger, M. Kolb, S. Neumeier, S. Gao, A. Hartmaier, K. Durst, M. Goken: Mater Des, 183 (2019) 108090.

[19] G. Sharma, R.V. Ramanujan, T.R.G. Kutty, G.P. Tiwari: Mater Sci Eng A, 278 (2000) 106-112.

[20] M. Akhtara, A. Khajuria, V.S. Kumar, R.K. Gupta, S.K. Albert: Physics of Metals and Metallography, 120 (2019) 672-685.

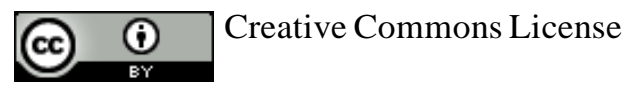

This work is licensed under a Creative Commons Attribution 4.0 International License. 